\title{
Single crystal to single crystal polymorphic phase transition of a silver nitrate 24-crown-8 complex and its pseudo-polymorphism $\dagger$
}

\author{
Jerome Girard and Katharina Fromm*
}

\begin{abstract}
A silver nitrate 24-crown-8 complex $\left[\mathrm{Ag}_{4}(24 \text {-crown-8)(NO})_{4}\right](\mathbf{1})$ was synthesized, showing a single crystal to single crystal polymorphic phase transition induced by temperature and leading to polymorph $\left[\mathrm{Ag}_{4}(24-\mathrm{crown}-8)\left(\mathrm{NO}_{3}\right)_{4}\right] \mathbf{1}^{\prime}$. When this complex (1) is exposed to humidity or directly crystallized from a water containing solvent, a pseudo polymorph $\left[\mathrm{Ag}_{4}\left(24\right.\right.$-crown-8) $\left.\left(\mathrm{NO}_{3}\right)_{4}\left(\mathrm{H}_{2} \mathrm{O}\right)_{2}\right](2)$ with two additional water molecules is obtained. When this pseudo polymorph is heated above $100^{\circ} \mathrm{C}$, it may be transformed back into the first structure (1).
\end{abstract}

\section{Introduction}

Crown ethers are a family of compounds widely used in chemistry for many different applications: they have high affinity for binding specific cations depending on their size, e.g. 18crown-6 preferentially binds potassium ions, ${ }^{1}$ while 12 -crown-4 is well suited for lithium ions. ${ }^{2}$ Crown ethers are also used in supramolecular chemistry, e.g. in the construction of rotaxanes, ${ }^{3}$ or to generate synthetic ion channels for transport studies of specific cations. ${ }^{4}$ Coordination of 24-crown-8 is one of the less studied of the crown ether family, as a search in the Cambridge Structural Database shows more than 2000 hits for the 18crown-6 and more than 15000 papers on SciFinder $\AA$ whereas the same research for the 24-crown-8 gives only one structure ${ }^{5}$ and about 1300 papers.

Single crystal to single crystal transformations have received a lot of attention in solid state chemistry. ${ }^{6-8}$ Nevertheless only few examples are reported in the literature. Single crystal to single crystal transformations are usually induced by light, ${ }^{8}$ temperature $^{7}$ or guest introduction. ${ }^{9}$ Most of these transformations are in fact polymorphisms. Polymorphism is a multidisciplinary term (biology, computing, chemistry...), referring in chemistry to the ability of a compound to exist in multiple forms in the solid state. Different types of polymorphism ${ }^{10}$ exist in crystallography: the first one is conformational polymorphism when the same compound can have different conformers. The second one is packing polymorphism, occurring when the molecule has the same conformation but a different packing. The last one is called pseudo-polymorphism and describes crystalline forms that differ

Department of Chemistry, University of Fribourg, Chemin du Musée 9, CH-1700 Fribourg, Switzerland.E-mail: katharina.fromm@unifr.ch; Fax: +41 263009738; Tel: +41 263008732

$\uparrow$ Electronic supplementary information (ESI) available: Additional figures of packing, lists of $\mathrm{Ag}-\mathrm{O}$ bond lengths, DSC analysis, figures with thermal ellipsoids (Figs. S9,10 and 11) and crystallographic data for $\mathbf{1}, \mathbf{1}$ ' and $\mathbf{2}$ are given. CCDC reference numbers 875797-875799. in nature or stoichiometry of included solvent molecules. Pseudopolymorphs include examples with solvent on isolated lattice sites, in lattice channels as well as metal-ion coordinated solvates. ${ }^{11}$ This term is controversial: It is well recognized and used in the pharmaceutical area and recognized by the FDA. ${ }^{12}$ In chemistry some researchers think that this term should be replaced by "solvate" or "hydrate", 13 while others argue that this term is now too common and popular and should be used to designate solvates and hydrates. ${ }^{14}$ Polymorphism in general can lead to very different physical properties of the material (e.g. stability, solubility in solvent etc.). ${ }^{15}$

In our group, we are interested in polymorphism ${ }^{16}$ and pseudo polymorphism of antimicrobial silver-containing compounds ${ }^{17}$ in order to control their structure and silver-release properties for tuning antimicrobial properties and biocompatibility. We are also interested in crown ether compounds, particularly in the formation of one-dimensional channels obtained with the dibenzo-18-crown-6 in order to analyze ion transport. ${ }^{18}$ In this work, we present a single crystal to single crystal transformation of a tetra silver nitrate 24-crown-8 complex, $\left[\mathrm{Ag}_{4}\right.$ (24-crown8) $\left.\left(\mathrm{NO}_{3}\right)_{4}\right]$ : a reversible packing polymorphism induced by temperature, thus a phase transition, and also a reversible pseudo polymorphism induced by the presence of water to yield $\left[\mathrm{Ag}_{4}\left(24\right.\right.$-crown-8) $\left.\left(\mathrm{NO}_{3}\right)_{4}\left(\mathrm{H}_{2} \mathrm{O}\right)_{2}\right]$.

\section{Experimental}

\section{Materials and methods}

All chemicals were standard reagent grade and were used without further purification. Air-sensitive and/or moisturesensitive reactions were conducted under a dry argon atmosphere. ${ }^{1} \mathrm{H}$ and ${ }^{13} \mathrm{C}-\mathrm{NMR}$ spectra were recorded with $300 \mathrm{MHz}$ spectrometer with residual solvent signals used as reference. DSC analyses were done on a Mettler-Toledo DSC 30 with a TC 15 controller and TGA were performed on a TGA/SDTA 851 e. All single crystals were mounted on loops and all geometric and 
intensity data were taken from one single crystal. Data collection, using Mo-K $\alpha$ radiation $(\lambda=0.71073 \AA)$ was performed at $273 \mathrm{~K}$ for $\mathbf{1}$ and $\mathbf{2}, 200 \mathrm{~K}$ for $\mathbf{1}^{\prime}$ on a STOE IPDS-II diffractometer equipped with an Oxford Cryosystems open flow cryostat. ${ }^{19}$ Absorption correction was partially integrated in the data reduction procedure. ${ }^{20}$ The structure was solved by SIR $2004^{21}$ or SHELX-97 and refined using full-matrix least-squares on $F^{2}$ with the SHELX-97 package. ${ }^{21}$ All heavy atoms could be refined anisotropically. Hydrogen atoms were introduced as fixed contributors when a residual electronic density was observed near their expected positions. Powder X-ray diffractogram were collected on a Stoe StadiP using $\mathrm{Cu}-\mathrm{K}_{\alpha 1}$ radiation $(\lambda=1.5406 \AA)$ or on a STOE IPDS-IIT diffractometer using $\mathrm{Cu}-\mathrm{K}_{\alpha}$ radiation $(\lambda=1.54186 \AA)$ both equipped with an Oxford Cryosystems open flow cryostat.

\section{Synthesis}

24-crown-8 was synthesized following the procedure of Talanov and Bartsch. ${ }^{22}$ Silver nitrate complex $\left[\mathrm{Ag}_{4}\left(24\right.\right.$-crown-8) $\left.\left(\mathrm{NO}_{3}\right)_{4}\right]$ (1) was made by mixing 4 equivalents of silver nitrate and one equivalent of 24-crown-8 in methanol. Slow evaporation of methanol gives suitable crystals for X-ray measurement (yield $>90 \%$ ). ${ }^{1} \mathrm{H}$ NMR (300 MHz, CD 3 OD) $\delta 3.70$ (s, $\left.32 \mathrm{H}\right)$ IR $v=$ 2923 (w), 2877 (w), 1452 (m), 1327 (s), 1269 (s), 1242 (m), 1280 (m), 1075 (s), 949 (s), 841 (m), 818 (m). Bulk product was analyzed by XRPD and does not show any impurity or byproducts.

Dihydrate silver complex $\left[\mathrm{Ag}_{4}\left(24\right.\right.$-crown-8) $\left.\left(\mathrm{NO}_{3}\right)_{4}\left(\mathrm{H}_{2} \mathrm{O}\right)_{2}\right]$ (2) can be made by placing (1) in a humid environment, or by reacting four equivalents of silver nitrate and one equivalent of 24-crown-8 in a mixture of methanol and water (yield $>90 \%$ ). ${ }^{1} \mathrm{H}$ NMR (300 MHz, CD 3 OD) $\delta 3.71(\mathrm{~s}, 32 \mathrm{H}) 4.87$ (s, 4 H) IR $v=$ 3520 (w), 3350 (w), 2929 (w), 2880 (w), 1630 (w), 1455 (m), 1303 (s), 1279 (s), 1283 (m), 1075 (s), 949 (s), 844 (m), 813 (m). Bulk product was analyzed by XRPD and does not show any impurity or byproducts.

\section{Results and discussion}

Analysis of product 1 by single crystal diffraction at $273 \mathrm{~K}$ reveals a 24-crown-8 ligand coordinating to four silver nitrate entities in the orthorhombic space group $\operatorname{Ibca}$ ( Fig. 1).The asymmetric unit is composed of half of a crown ether molecule, two silver atoms, one full nitrate and two half nitrate anions. The other half is constructed by a 2 -fold axis passing through $\mathrm{O} 1(0$, $1 / 4,0.0092(2))$ and O5 $(0,1 / 4,0.2443(2))$ of the crown ether ligand. Each silver ion is binding to three oxygen atoms of the crown ether with an average distance of 2.55(1) $\AA$ for $\mathrm{Ag} 1$ and 2.52(4) $\AA$ for Ag2 (all Ag-O distances until $3.05 \AA$ are listed in Table S1 for the three structures described in this manuscript. Distances greater than $3.05 \AA$ contribute to the bond valence sum with less than 0.04, and we choose thus this distance as a limit for the $\mathrm{Ag}$ $\mathrm{O}$ interactions $\mathrm{s}^{23}$ as derived from the software PLATON. ${ }^{24}$ ). Two nitrate anions (N1, O6, O7 and $\mathrm{O} 8$ and its symmetry equivalent) interact in a bidentate fashion with Ag1 (2.350(4) $\AA$ for Ag1-O6 and 2.433(5) $\AA$ for Ag1-O9) and Ag2 (2.364(4) $\AA$ for Ag2-O6 and 2.679(5) $\AA$ for Ag2-O8), O6 acting as bridge between the two silver ions. Ag1 is also connected to the nitrate anion around N2 with a distance of 2.432(4) $\AA$ for Ag1-O9 and 2.7268(6) $\AA$ for

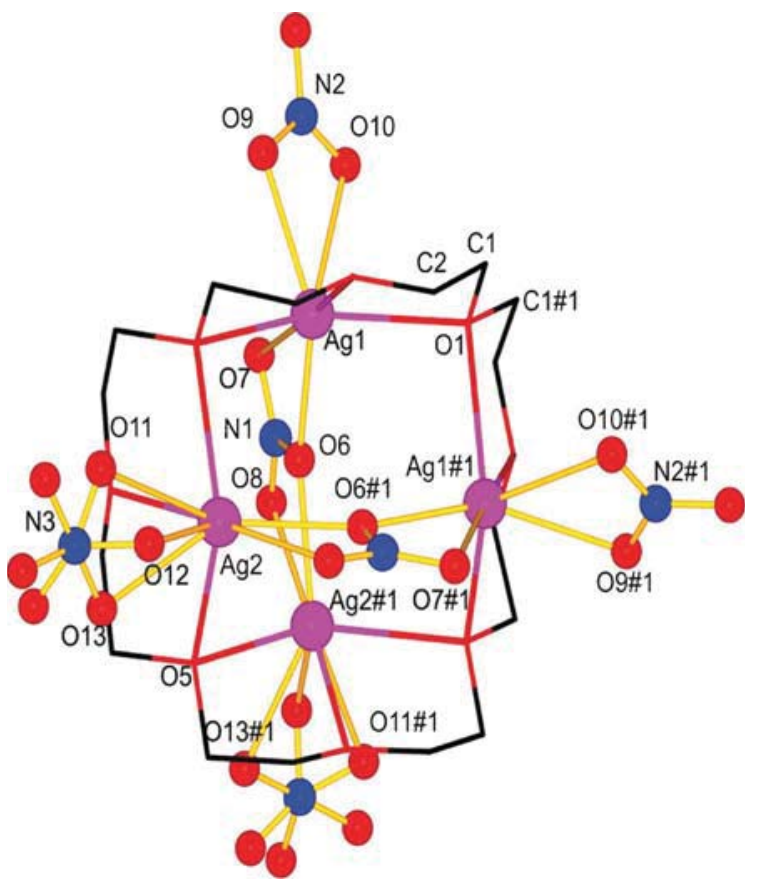

Fig. 1 Excerpt of the coordination polymer of 1. Crown ether atoms are shown as wire models and hydrogen atoms are omitted for clarity. (\#1: $-x, 0.5-y, z)$.

Ag1-O10. Due to the rotational disorder around N3 of one of the nitrate anions $(\mathrm{N} 3, \mathrm{O} 11, \mathrm{O} 12, \mathrm{O} 13)$ showing two different randomly distributed positions, $\mathrm{Ag} 2$ can be considered as six- or seven-coordinated, with contributions from three oxygen atoms of the crown ether ligand and three or four oxygen atoms from two different nitrate anions. Depending on the position of the disordered nitrate anion, the distance Ag2-O is shorter (2.19(3) $\AA$ ) upon monodentate binding than if the nitrate acts as bidentate ligand (2.60(3) $\AA$ and 2.80(2) $\AA$ ).

The average $\mathrm{Ag}-\mathrm{Ag}$ distance between the metal ions of a "ring" is 3.91(1) $\AA$. The inorganic part of the structure forms layers of silver nitrate along the $b$ - and the $c$-axis, these layers are composed of silver nitrate chains along the $c$-axis (Fig. S1 $\dagger$ ). The crown ether ligand acts as connector between these chains and layers. Vice versa, one can consider the nitrate anions as

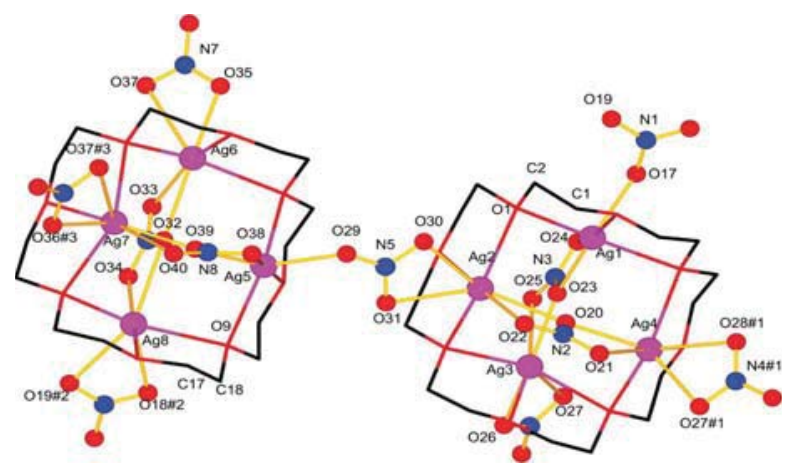

Fig. 2 Excerpt of the coordination polymer of $\mathbf{1}^{\prime}$. Crown ether molecules are shown in wire mode and hydrogen atoms are omitted for clarity. (\#1: $1-x, 0.5+y,-0.5-z \# 2:-1+x, y, z \# 3:-x, 0.5+y$, $-0.5-z)$ 


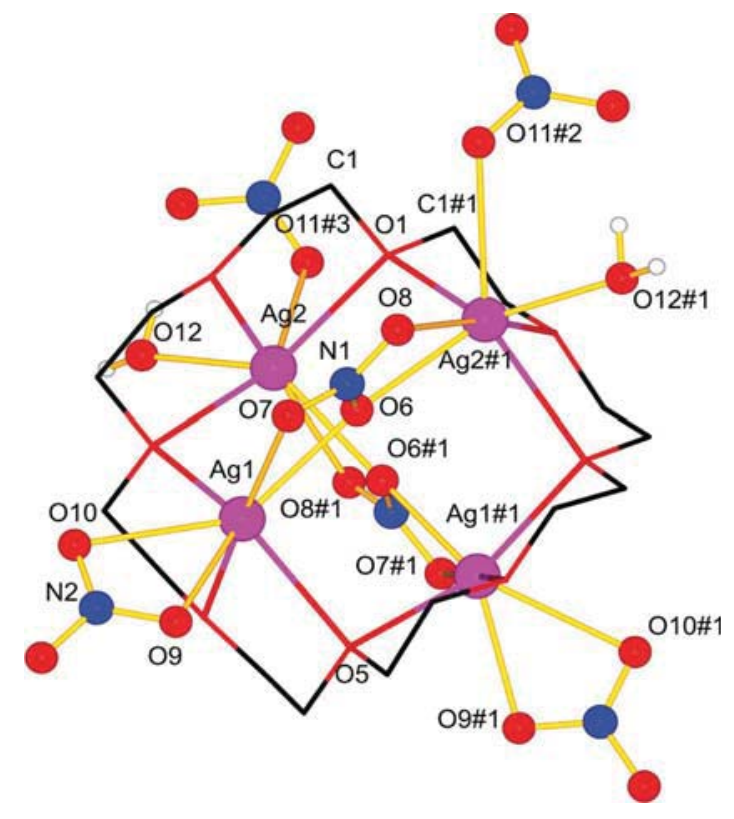

Fig. 3 Excerpt of the coordination polymer of 2. Crown ether ligands are shown in wire mode and some hydrogen atoms are omitted for clarity. (\#1: $2-x, y, 1.5-z \# 2: 0.5+x, 0.5+y, z \# 3: 1.5-x, 0.5+y$, $1.5-z)$.

connecting ligands between the crown ether-silver complexes, generating a 3D network (Fig. S2 $\uparrow$ ). However, only two out of the four nitrate ligands act as bridging ligands between the crown ether complexes, while the other to only connect to silver ions of one complex. The packing of $\mathbf{1}$ shows small voids in the structure. Calculation of the contact surface of the voids gives 8 voids of $22 \AA^{3}$ per unit cell for a total of $2.8 \%$ of the unit cell.

Upon cooling of a crystal of $\mathbf{1}$ to $200 \mathrm{~K}$ or less, it undergoes a phase transition into a monoclinic system, yielding $\mathbf{1}^{\prime}$. The unit cell of $\mathbf{1}^{\prime}$ contains two crown ether molecules and eight silver nitrate units. The crown ether molecules maintain the same conformation as in $\mathbf{1}$, and each ligand coordinates again to four silver atoms. Two silver atoms $\mathrm{Ag} 1$ and $\mathrm{Ag} 5$ are now hexacoordinated, while the six other silver ions are heptacoordinated. The two crown ether silver complexes of the unit cell are linked by a nitrate anion (N5, O29, O30 and O31) (Fig. 2).

For the first crown ether molecule ( $\mathrm{C} 1$ to $\mathrm{C} 16)$, two nitrate anions (around N1 and N4) are binding to silver ions (Ag1 to
Ag3) coordinated by this crown ether ligand, while the third nitrate anion around $\mathrm{N} 2$ forms two bidendate interactions with Ag4 (2.422(5) ̊̊ for Ag4-O20, 2.702(7) Å for Ag4-O21) and Ag2 (2.472(5) $\AA$ for Ag2-O20 and 2.527(5) $\AA$ for Ag2-O22), where O20 connects these two silver ions. The fourth nitrate ion around $\mathrm{N} 3$ interacts similarly with $\mathrm{Ag} 1$ (2.316(5) $\AA$ for $\mathrm{Ag} 1-\mathrm{O} 23$ and 2.800(7) $\AA$ for Ag1-O24) and Ag3 (2.293(5) $\AA$ for Ag3-O23 and 2.991(7) $\AA$ for Ag3-O25) with O23 as bridging atom between the two silver ions. Each of the four silver ions is also coordinated by three oxygen atoms of the crown ether moiety. The second crown ether ligand (C17 to $\mathrm{C} 32$ ), four silver atoms (Ag5 to $\mathrm{Ag} 8)$ and four nitrate moieties. The coordination scheme of the silver ions is very similar to the one of the first entity: one nitrate anion (N7, $\mathrm{O} 35, \mathrm{O} 36$ and $\mathrm{O} 37$ ) is binding to $\mathrm{Ag} 6$ with distances of 2.342(7) $\AA$ for $\mathrm{O} 35$ and 2.862(7) $\AA$ for O37. A second nitrate (N6, O32, $\mathrm{O} 33$ and $\mathrm{O} 34)$ forms two bidendate interactions with $\mathrm{Ag} 6$ (2.535(5) $\AA$ for Ag6-O32 and 2.517(6) $\AA$ for Ag6-O33) and Ag8

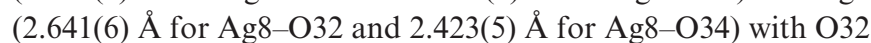
bridging Ag6 and Ag8. The third nitrate (N8, O37, O38 and O39) interacts with Ag5 (2.909(7) $\AA$ for Ag5-O38 and 2.300(5) $\AA$ for $\mathrm{Ag} 5-\mathrm{O} 39)$ and $\mathrm{Ag} 7$ (2.298(5) $\AA$ for Ag7-O39 and 2.985(8) $\AA$ for $\mathrm{Ag} 7-\mathrm{O} 40$ ) with $\mathrm{O} 39$ as bridging atom. A final nitrate anion (N5, O29 to O31) forms a $\mu_{2}-\eta^{1}: \eta^{2}$ bridge between Ag2 and Ag5, connecting the two polyether-silver entities of the asymmetric unit.

All nitrate ions (around N1, N4 and N7), which only bind once or twice to silver ions of the asymmetric unit, also connect to silver atoms of neighbour crown ether molecules of the next asymmetric units (Fig. S3 $\uparrow$ ), leading thus to a 3D-framework (Fig. S4†). The inorganic part of the structure is again composed of layers of silver nitrate along the $a$ - and the $c$-axis, with chains of silver nitrate along the $c$-axis (Fig. S5 $\dagger$ ).

At first sight, one might link the difference between $\mathbf{1}$ and $\mathbf{1}^{\prime}$ solely to the disorder of the nitrate ions described in $\mathbf{1}$. This would then represent a "partial melting" of the structure. However, the main differences between $\mathbf{1}$ and $\mathbf{1}$ ' are not only the position of the nitrate anions, but also the way the nitrate anions link two crown ether moieties. If we assume the nitrate anion as a large sphere with the nitrogen atom as center (thus not taking into account the disorder of the $\mathrm{O}$-atoms in 1), the angles $\mathrm{Ag}-\mathrm{N}-$ $\mathrm{Ag}$ for $\mathbf{1}$ between silver ions and bridging nitrate anions are $153.8(2)^{\circ}$ and $133.9(2)^{\circ}$, whereas for $\mathbf{1}^{\prime}$ these angles are $146.3(3)^{\circ}$, $144.5(3)^{\circ}, 141.9(3)^{\circ}$ and $129.9(3)^{\circ}$. This difference in the nitrate position is significant and can be easily seen by comparing the

Table 1 Crystallographic parameters for $\mathbf{1}, \mathbf{1}^{\prime}$ and $\mathbf{2}$

\begin{tabular}{|c|c|c|c|}
\hline Formula & $\begin{array}{l}1 \\
\text { C8 H16 Ag2 N2 O10 }\end{array}$ & $\begin{array}{l}\mathbf{1}^{\prime} \\
\text { C32 H64 Ag8 N8 O40 }\end{array}$ & $\begin{array}{l}2 \\
\mathrm{C} 16 \text { H36 Ag4 N4 O22 }\end{array}$ \\
\hline Formula weight & 515.97 & 2063.87 & 1067.97 \\
\hline Crystal system & orthorhombic & monoclinic & monoclinic \\
\hline Space group & Ibca & $P 2_{1} / c$ & $C 2 / c$ \\
\hline Temp. (K) & 273 & 200 & 273 \\
\hline$a, \AA$ & $13.4204(6)$ & $16.3286(8)$ & $12.1262(13)$ \\
\hline$b, \AA$ & $16.5076(7)$ & $13.4452(5)$ & $17.6035(16)$ \\
\hline$c, \AA$ & $28.1263(13)$ & $28.0645(14)$ & $14.7902(12)$ \\
\hline$\beta, \operatorname{deg}$ & 90 & $90.800(4)$ & $93.461(8)$ \\
\hline$V, \AA^{3}$ & $6231.1(5)$ & $6160.7(5)$ & $3151.4(5)$ \\
\hline$Z$ & 16 & 4 & 4 \\
\hline$R$ (int) & 0.0456 & 0.0792 & 0.0848 \\
\hline$R_{1}(\%)$ & 3.82 & 4.29 & 3.55 \\
\hline
\end{tabular}


packing along the $b$ axis for $\mathbf{1}$ and the $a$-axis for $\mathbf{1}^{\prime}$ (Fig. S1 and $\mathrm{S} 4 \uparrow)$. It results in a dramatic loss of symmetry not only around the disordered nitrate ion around N3, but also around the second bridging nitrate ion around N2 of 1 (compare Fig. S1 bottom with Fig. S5 bottom $\dagger$ ).

To study the reversibility of this transformation, we performed a DSC analysis of compound $\mathbf{1}$. An exothermic peak at $204 \mathrm{~K}$ is found for the transformation of $\mathbf{1}$ to $\mathbf{1}^{\prime}$ during the cooling and an endothermic peak at $214 \mathrm{~K}$ for the transformation of $\mathbf{1}^{\prime}$ to $\mathbf{1}$ during the heating cycle, this giving rise to a small hysteresis. After fifty heating and cooling cycles, a conversion of $\mathbf{1}$ to $\mathbf{1}^{\prime}$ and back of $95 \%$ is still observed (Fig. S6†).

When $\mathbf{1}$ is exposed to humidity or when recrystallizing $\mathbf{1}$ from a mixture of water and methanol, we obtained a third structure $\left[\mathrm{Ag}_{4}\left(24\right.\right.$-crown-8) $\left.\left(\mathrm{NO}_{3}\right)_{4}\left(\mathrm{H}_{2} \mathrm{O}\right)_{2}\right]$, 2, which crystallizes in the monoclinic space group $C 2 / c$. One crown ether ligand and four silver nitrate entities are maintained per formula unit with, in addition, two water molecules (Fig. 3).

The asymmetric unit of $\mathbf{2}$ is composed of half of a crown ether ligand, two silver atoms $\mathrm{Ag} 1$ and $\mathrm{Ag} 2$, two nitrate ions and one water molecule. The other half of the complex is constructed by a 2-fold axis passing through O1 $(1,0.0389(3), 3 / 4)$ and O5 $(1,0.4157(3), 3 / 4)$. Ag1 and $\mathrm{Ag} 2$ are 7 -coordinated each by three oxygen atoms of the crown ether with an average distance of 2.547(6) $\AA$ for Ag1 and 2.601(5) $\AA$ for Ag2. The nitrate (N1, O6, $\mathrm{O} 7$ and O8) forms bidendate interactions with Ag1 (2.453(4) $\AA$ for Ag1-O6 and 2.626(5) $\AA$ for Ag1-O7) and Ag2 across the

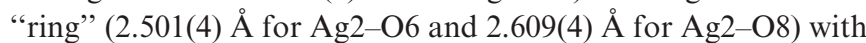
O6 bridging the two silver ions. The second nitrate around N2 acts as bidentate ligand towards Ag1 (2.485(5) $\AA$ for Ag1-O9 and 2.699(6) $\AA$ for Ag1-O10) and as monodentate ligand to Ag2 of a next crown ether silver complex (2.862(5) $\AA$ for Ag2-O11). This nitrate anion is thus the connector between the crown ether silver moieties. Finally, an oxygen atom of a water molecule, O12, is coordinated to Ag2 with a distance of 2.406(6) $\AA$. The hydrogen atoms of the water molecules form $\mathrm{H}$-bonds ${ }^{25}$ with two bridging nitrate ions with a distance of 1.95(4) $\AA$ for H12B-O9 and 2.35(7) $\AA$ for H12A-O7. Four symmetry related nitrate anions (around N2) are thus binding to neighbour crown ethersilver complexes to form a two dimensional framework along the $a$ and $b$ axes (Fig. S7).

In order to check if a dehydration of the complex will destroy the structure or not, we performed a DSC analysis (Fig. S8). The heating of the sample shows an endothermic peak at $370 \mathrm{~K}$, which corresponds to the dehydration of $\mathbf{2} .2$ then transforms into $\mathbf{1}$, as confirmed by the subsequent cooling of the obtained dehydrated sample, showing an exothermic peak at $204 \mathrm{~K}$ similar to the one for the transformation of $\mathbf{1}$ to $\mathbf{1}^{\prime}$. A following heating cycle shows again an endothermic peak at $214 \mathrm{~K}$ for the transformation of $\mathbf{1}^{\prime}$ to $\mathbf{1}$.

The transformation from $\mathbf{1}$ to $\mathbf{1}^{\prime}$ leads to a small change in the unit cell, except for $\beta$ with a variation of $0.8^{\circ}$ (Table 1 ). The cell axes $a$ and $b$ are exchanged and show the largest difference between the $b$-axis of 1 with $16.5076(7) \AA$ and the $a$-axis of $1^{\prime}$ with $16.3286(8) \AA$, which is significant.

In order to verify that all transformations are single crystal to single crystal transitions, a crystal of $\mathbf{2}$ was placed in an image plate x-ray diffractometer at $290 \mathrm{~K}$. A few frames were recorded in order to confirm the unit cell, and then a powder

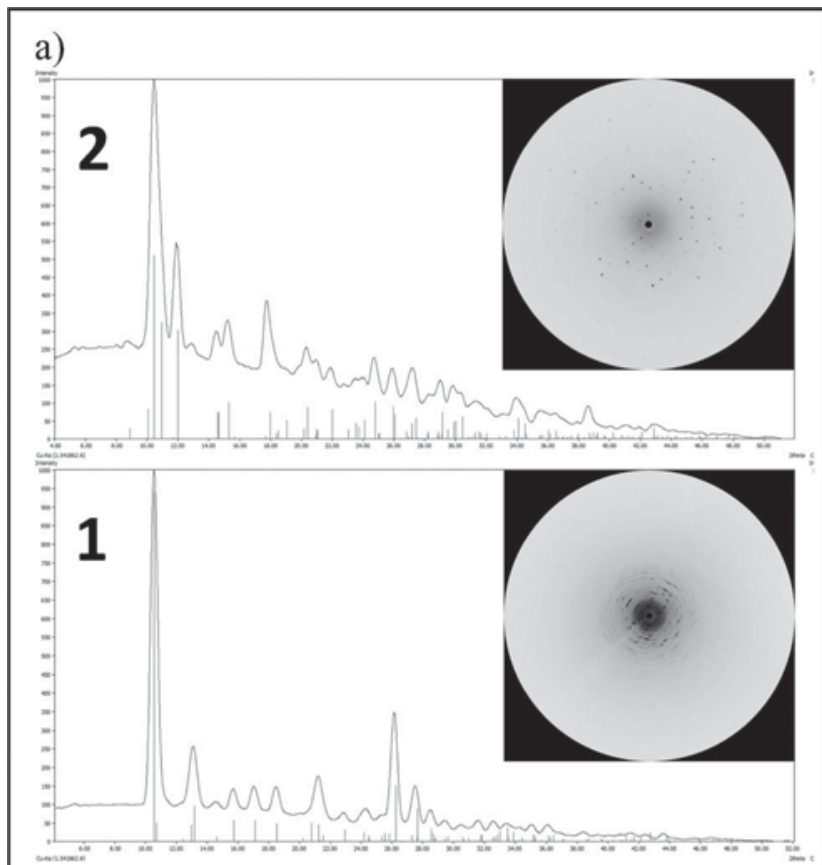

b)

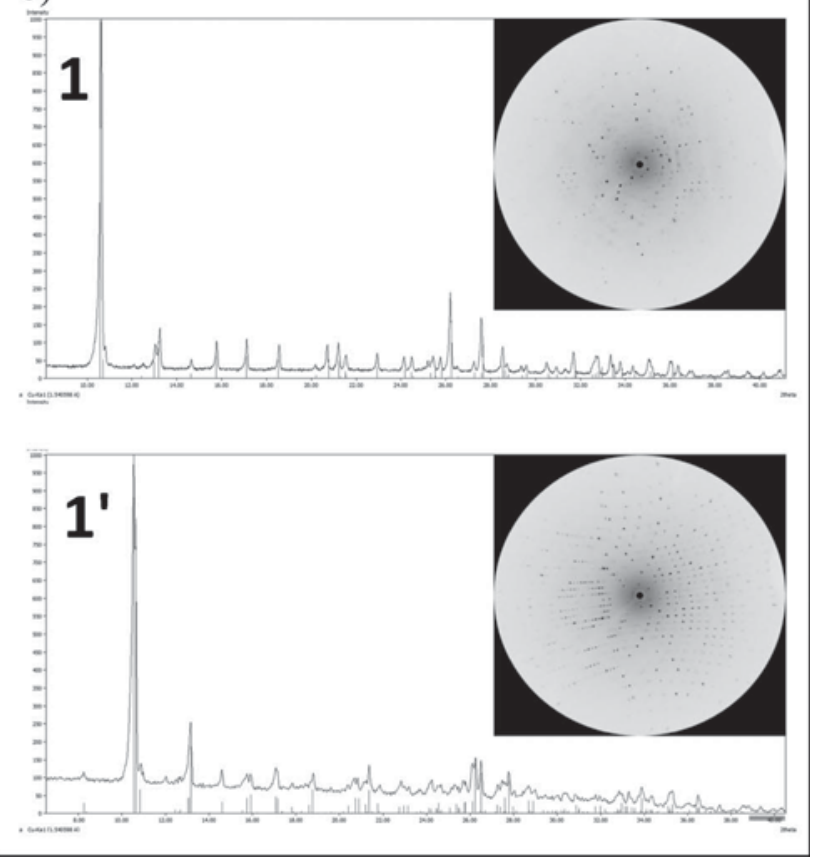

Fig. 4 a) Powder diffraction of 2 before (top) and after (bottom) heating to $390 \mathrm{~K}$. b) Powder diffraction of $\mathbf{1}$ at $300 \mathrm{~K}$ (top) and after cooling to $150 \mathrm{~K}$ (bottom). Recorded frames are shown in the corner.

diffractogram was recorded to confirm the structure and its crystallinity. Then the crystal was heated to $390 \mathrm{~K}$ with a ramp of $4 \mathrm{~K}$ per hour, held at this temperature for $10 \mathrm{~min}$ and then cooled down to $290 \mathrm{~K}$. Again, a few frames and a powder diffractogram were recorded. A similar procedure was used with a crystal of $\mathbf{1}$, cooling it down to $150 \mathrm{~K}$ in order to observe its transformation to $\mathbf{1}^{\prime}$ (Fig. 4).

The transformation from $\mathbf{2}$ to $\mathbf{1}$ leads to microscopic damage inside the crystal. This is due to the evaporation of the water and is observed under the microscope in form of tiny bubbles in the 
crystal. Nevertheless, the crystal still holds together in one piece, even if the recorded frames show a transition to a polycrystalline material. A slower heating ramp gives better results due to less strain applying on the crystal during the water evaporation process. Transformation from $\mathbf{1}$ to $\mathbf{1}^{\prime}$ does not show any microscopic damage of the crystal, and the recorded frames indicate diffraction patterns of a single crystal.

\section{Conclusions}

In summary, we have successfully synthesized a 24-crown-8 silver nitrate complex, which exists in two different polymorphs as a function of temperature. Transitions between these two phases occur reversibly in single crystal to single crystal transitions. A hydrated pseudo-polymorph is obtained upon exposure of $\mathbf{1}$ to humidity or by attempts of crystallizing 1 from a watercontaining solvent. Two molecules of water are then additionally coordinated to the silver atoms. This pseudo polymorphism is also reversible, but single crystal damage occurs, while crystallinity is maintained during the evaporation of water.

\section{Acknowledgements}

The authors thank the Swiss National Science Foundation, the University of Fribourg and the Fribourg Center for Nanomaterials FriMat for generous support.

\section{References}

1 L. X. Dang, J. Am. Chem. Soc., 1995, 117, 6954-6960.

2 (a) Z. X. Shu, J. Electrochem. Soc., 1993, 140, 922; (b) D. Ray, D Feller, M. B. More, E. D. Glendening and P. B. Armentrout, J. Phys. Chem., 1996, 100, 16116-16125; (c) I.-H. Chu, H. Zhang and D. V. Dearden, J. Am. Chem. Soc., 1993, 115, 5736-5744.

3 (a) P. R. Ashton, R. Ballardini, V. Balzani, I. Baxter, A. Credi, M. C. T. Fyfe, M. T. Gandolfi, M. Gomez-Lopez, M.-V. Martinez-Diaz, A. Piersanti, N. Spencer, J. F. Stoddart, M. Venturi, A. J. P. White and D. J. Williams, J. Am. Chem. Soc., 1998, 120, 11932-11942; (b) J. D. Badjic, C. M. Ronconi, J. F. Stoddart, V. Balzani, S. Silvi and A. Credi, J. Am. Chem. Soc., 2006, 128, 1489-1499; (c) A. Harada, Acta Polym., 1998, 49, 3-17; (d) M.-V. Martinez-Diaz, N. Spencer and J. F. Stoddart, Angew. Chem., Int. Ed. Engl., 1997, 36, 1904-1907; (e) P. R. Ashton, P. T. Glink, J. F. Stoddart, P. A. Tasker, A. J. P. White and D. J. Williams, Chem.-Eur. J., 1996, 2, 729-736.

4 (a) D. A. Morton-Blake, B. Jenkins and I. Blake, Mol. Simul., 2011, 37, 1077-1084; (b) D. A. Morton-Blake and K. Korpela, Soft Matter, 2010, 6, 558-567; (c) T. Nakamura, T. Akutagawa, K. Honda, A. E. Underhill, A. T. Coomber and R. H. Friend, Nature, 1998, 394, 159-162; (d) V. Percec, G. Johansson, J. Heck, G. Ungar and S. V. Batty, J. Chem. Soc., Perkin Trans. 1, 1993, 1411-20.

5 N. Georges, S. J. Loeb, J. Tiburcio and J. A. Wisner, Org. Biomol. Chem., 2004, 2, 2751.

6 (a) M. Kawano and M. Fujita, Coord. Chem. Rev., 2007, 251, 2592-2605; (b) M. P. Suh, J. W. Ko and H. J. Choi, J. Am. Chem. Soc., 2002, 124, 10976-10977; (c) C.-L. Chen, A. M. Goforth, M. D.
Smith, C.-Y. Su and H.-C. Zur Loye, Angew. Chem., Int. Ed., 2005, 44, 6673-6677.

7 J.-P. Zhang, Y.-Y. Lin, W.-X. Zhang and X.-M. Chen, J. Am. Chem. Soc., 2005, 127, 14162-14163.

8 N. L. Toh, M. Nagarathinam and J. J. Vittal, Angew. Chem., Int. Ed., 2005, 44, 2237-2241.

9 (a) T. K. Maji, G. Mostafa, R. Matsuda and S. Kitagawa, J. Am. Chem. Soc., 2005, 127, 17152-17153; (b) G. van Koten, M. Albrecht, M. Lutz and A. L. Spek, Nature, 2000, 406, 970-974.

10 J. Bernstein, Polymorphism in molecular crystals, Clarendon Press, Oxford, 2002, vol. 14.

11 (a) A. Y. Robin and K. M. Fromm, Coord. Chem. Rev., 2006, 250, 2127-2157; (b) C. B. Aakeröy, A. M. Beatty and D. S. Leinen, Cryst. Growth Des., 2001, 1, 47-52.

12 Guidance for Industry, ANDAs: Pharmaceutical Solid Polymorphism; Food and Drug Adminstration, Silver Spring, 2007.

13 (a) K. R. Seddon, Cryst. Growth Des., 2004, 4, 1087; (b) J. Bernstein, Cryst. Growth Des., 2005, 5, 1661-1662.

14 (a) G. R. Desiraju, CrystEngComm, 2003, 5, 466-467; (b) A. Nangia and G. R. Desiraju, Chem. Commun., 1999, 605-606.

15 (a) J. Bernstein, J. Phys. D: Appl. Phys., 1993, 26, B66; (b) L. Huang, Adv. Drug Delivery Rev., 2004, 56, 321-334.

16 (a) A. Y. Robin, K. M. Fromm, H. Goesmann and G. Bernardinelli, CrystEngComm, 2003, 5, 405-410; (b) A. Crochet, E. Kottelat, A. Fleury, M. Neuburger and K. M. Fromm, Z. Anorg. Allg. Chem., 2011, 637, 672-675.

17 (a) J. L. Sague, M. Meuwly and K. M. Fromm, CrystEngComm, 2008, 10, 1542-1549; (b) T. V. Slenters, J. L. Sague, P. S. Brunetto, S. Zuber, A. Fleury, L. Mirolo, A. Y. Robin, M. Meuwly, O. Gordon, R. Landmann, A. U. Daniels and K. M. Fromm, Materials, 2010, 3, 3407-3429.

18 (a) M. Dulak, R. Bergougnant, K. M. Fromm, H. R. Hagemann, A. Y. Robin and T. A. Wesolowski, Spectrochim. Acta, Part A, 2006, 64, 532-548; (b) K. M. Fromm and R. D. Bergougnant, Solid State Sci., 2007, 9, 580-587; (c) M. G. Zolotukhin, M. d. C. G. Hernandez, A. M. Lopez, L. Fomina, G. Cedillo, A. Nogales, T. Ezquerra, D. Rueda, H. M. Colquhoun, K. M. Fromm, A. Ruiz-Trevino and M. Ree, Macromolecules, 2006, 39, 4696-4703; (d) K. M. Fromm, R. D. Bergougnant and A. Y. Robin, Z. Anorg. Allg. Chem., 2006, 632, 828-836; (e) K. M. Fromm, E. D. Gueneau, H. Goesmann and C. G. Bochet, Z. Anorg. Allg. Chem., 2003, 629, 597-600; (f) K. M. Fromm, E. D. Gueneau, J.-P. Rivera, G. Bernardinelli and H. Goesmann, $Z$. Anorg. Allg. Chem., 2002, 628, 171-178.

19 J. Cosier and A. M. Glazer, J. Appl. Crystallogr., 1986, 19, 105-107.

20 E. Blanc, D. Schwarzenbach and H. D. Flack, J. Appl. Crystallogr., 1991, 24, 1035-1041.

21 (a) M. C. Burla, R. Caliandro, M. Camalli, B. Carrozzini, G. L. Cascarano, L. de Caro, C. Giacovazzo, G. Polidori and R. Spagna, J. Appl. Crystallogr., 2005, 38, 381-388; (b) G. M. Sheldrick, SHELX97. Program for Crystal Structure Refinement, University of Göttingen, Germany, 1997.

22 V. S. Talanov and R. A. Bartsch, Synth. Commun., 1999, 29, 3555-3560.

23 (a) N. E. Brese and M. O'Keeffe, Acta Crystallogr., Sect. B: Struct. Sci., 1991, 47, 192-197; (b) I. D. Brown, The chemical bond in inorganic chemistry. The bond valence model, Oxford University Press, Oxford, 2009, vol. 12.

24 A. L. Spek, Acta Crystallogr., Sect. D: Biol. Crystallogr., 2009, 65, $148-155$.

25 (a) T. Steiner, Angew. Chem., Int. Ed., 2002, 41, 48-76; (b) M. C. Etter, Acc. Chem. Res., 1990, 23, 120-126. 